Research Article

\title{
Theoretical Investigation of Nonlinear Time-Dependent Behavior of Two-Way High-Strength Concrete Walls
}

\author{
Yue Huang $\mathbb{D}^{1,2}$ Rui Rao $\mathbb{D}^{2}{ }^{2}$ Yonghui Huang $\mathbb{D}^{2},{ }^{2}$ and Zilin Zhong ${ }^{2}$ \\ ${ }^{1}$ School of Civil Engineering, Qingdao University of Technology, Qingdao 266033, China \\ ${ }^{2}$ Guangzhou University-Tamkang University Joint Research Center for Engineering Structure Disaster Prevention and Control, \\ Guangzhou University, Guangzhou 510006, China
}

Correspondence should be addressed to Rui Rao; raorui@gzhu.edu.cn

Received 5 November 2019; Revised 17 February 2020; Accepted 13 March 2020; Published 20 April 2020

Academic Editor: Vincenzo Vespri

Copyright (C) 2020 Yue Huang et al. This is an open access article distributed under the Creative Commons Attribution License, which permits unrestricted use, distribution, and reproduction in any medium, provided the original work is properly cited.

High-strength concrete (HSC) walls have been increasingly used in the past decades. However, the time-dependent behavior of HSC wall panels in two-way action was not investigated, and the time effect of creep is not included in the design codes in most countries. For this purpose, the nonlinear long-term behavior of two-way HSC wall is investigated in this paper. A theoretical model is developed using time-stepping analysis considering geometric nonlinearity and creep of concrete. A rheological material model that is based on the generalized Maxwell chain is adopted to model the concrete creep. Von Karman plate theory is used to derive the incremental governing equations. The equations are solved numerically at each time step based on a Fourier series expansion of the deformations and loads and numerical multiple shooting method. It shows that the model can effectively predict the time-dependent behavior of two-way HSC panels, where the out-of-plane deflection and internal bending moments increase with time due to the combined effects of creep and geometric nonlinearity, which may ultimately lead to creep buckling failures. A parametric study shows that the long-term behavior of the panel is very sensitive to the in-plane load level and eccentricity, slenderness ratio, aspect ratio, and edge support conditions.

\section{Introduction}

High-strength concrete (HSC) has seen an increasing use in engineering structures in the past decades due to its superior material properties such as high strength and stiffness, enhanced durability, and lightweight in contrast to normalstrength concrete (NSC). One of the most significant applications of HSC is load-bearing walls used in multistorey and high-rise building. Load-bearing wall can be used as a single structural member in one-way action with restraint along top and bottom edges only, or in a wall group, such as lift and stair core, where they are restrained on four sides behaving in two-way action. The use of HSC may lead to thinner and hence more slender wall panels in practice, which highlights the need to investigate and revise their buckling capacity and its degradation with time due to the effect of concrete creep.
In general, wall panels normally carry vertical in-plane compression loads transferred from the superstructure and out-of-plane transverse loads, such as wind loads and hydrostatic pressures. In addition, wall panels are subjected to bending moments along top and bottom edges resulted from bending moments transferred from horizontal slab and beam at the connections and the eccentricity of in-plane compression loads. Consequently, wall panels can deform both axially and laterally. The coupling of lateral or out-ofplane deflection with vertical in-plane loads may produce additional bending moments due to geometric nonlinearity $\left(2^{\text {nd }}\right.$ order P- $\Delta$ effect $)$ at sections along the height of slender walls and enlarge the existing internal bending moments. This geometric nonlinear effect may lead slender panels to buckle. In light of the trend towards the use of more slender walls, this geometric nonlinear effect will become more predominate in determining wall panel behavior. 
Moreover, due to creep of concrete, slender HSC wall panel may undergo increased axial and out-of-plane deformation with time under sustained in-plane and out-ofplane loads. The combination of a sustained compression load with a gradually increasing deflection with time may lead to excessive lateral deflection and cracking of the wall over time in serviceable state and may lead to loss of stability ultimately due to second-order effect, so-called "creep buckling". Alternatively, the creep and shrinkage deformations may not necessarily lead to buckling failure, but they may increase the internal stresses and decrease the residual strength and the factor of safety of the wall member. In order to predict these effects for a reliable analysis and design of HSC panels, the variation in the creep strains with time and through the height and thickness of the wall, along with the geometric nonlinearity, need to be considered.

A sizable amount of studies was carried out with regard to one-way wall panels, particularly the strength of RC walls [1-7]. The outcomes from these research studies formed the basis for wall design formulae in most codes of practice, such as ACI318 [8] and AS3600 [9]. However, these investigations did not consider the time-dependent behavior of one-way walls. In addition, current design practice in many countries including US and Australia does not include these long-term effects in the wall panel design. The only studies regarding time-dependent performance of HSC wall panels were conducted by the first author $[10,11]$. Yet, these investigations only focused on their behavior in one-way action, and they did not recognize the contribution of two-way action to the load-carrying capacity of wall panel. The twoway behavior differs substantially from one-way behavior in the way that two-way wall panel develops biaxial curvatures under in-plane and/or out-of-plane loads in contrast to uniaxial curvature in one-way wall panel. As a result, the cracking pattern, deflection, and load-carrying capacity of two-way walls are different from those of one-way panels. Hence, the current one-way theoretical model cannot be used to predict the behavior of two-way panels.

A number of studies were reported in the literature in relation to two-way behavior of concrete wall panels. Swartz et al. [12] tested 24 rectangular concrete walls in two-way action which were subjected to uniaxial compression along shorter edges and simply supported along all edges. The concrete wall panels failed by buckling (biaxial curvature) at stress levels remarkably lower than the concrete compressive strength. Saheb and Desayi [13] tested 24 rectangular RC wall panels loaded eccentrically in two-way action. The panels were simply supported along four edges and were subjected to in-plane loading. It was found that the ultimate strength of wall panels in two-way action increased linearly with the increase in the aspect ratio as well as the vertical reinforcement. On the contrary, it reduced nonlinearly with the increase in thinness or slenderness ratios. Aghayere and Macgregor [14] reported test results on 9 concrete plates, simply supported along four edges and subjected to combined uniform in-plane compression and uniform transverse loading. In most axially loaded specimens, buckling of the reinforcement adjacent to the compression face took place at failure, and all final failures were compression failures due to crushing of the concrete. The cracks in the tension face tended to propagate in an orthogonal pattern. The presence of the axial in-plane load results in a reduction in the transverse load-carrying capacity due to the secondorder effect. Ghoneim and MacGregor [15] tested 19 twoway NSC plates that were subjected to combined in-plane compressive and transverse loads and simply supported on the four edges. The specimens tested under combined transverse and in-plane compressive loads failed explosively, indicating a buckling failure mode. The test results indicated that the slenderness of the plate and the loading sequence mainly determined the effect of the in-plane load on the lateral load capacity of RC plates. Ghoneim and MacGregor [16] found that, for stocky square plates, the presence of the in-plane load increased the lateral load capacity, as the geometrically nonlinear effect was insignificant. On the contrary, the presence of the in-plane load resulted in substantial reduction in the lateral load capacity of slender plates since the second-order effect of the in-plane load dominated the behavior. Sanjayan and Maheswaran [17] carried out experiments on 8 high-strength concrete walls loaded eccentrically with simple support conditions along 4 edges. It was found that the load capacity of the wall was significantly influenced by the eccentricity of in-plane loading, while it was insensitive to the concrete strength. In addition to the experimental investigations, a small amount of analytical studies have been reported with regard to the short-term behavior of two-way concrete wall panels [18-21]. Simply supported two-way panels that carried outof-plane transverse loads and various in-plane loads were investigated in these studies. The load-displacement responses of the specimens were obtained either by implementing finite element (FE) analysis or based on assumed deflection function. It was found that the ultimate strength of the two-way panels decreased with the increase in slenderness ratio.

Nonetheless, all aforementioned studies focused on short-term behavior of two-way concrete wall panels. To the authors' knowledge, no public literature has been reported on the long-term behavior of two-way HSC walls that are subjected to sustained loads. Therefore, the main purpose of this paper is to theoretically investigate the time-dependent performance of HSC walls in two-way action under the influence of concrete creep. A well-established model has been developed by the first author [22] that is capable of estimating the long-time nonlinear behavior of slender HSC wall panels under axial compression. The capability of the analytical model is demonstrated by good correlations between predicted and experimental results. Based on that, a new theoretical model that utilizes the mechanics of thin plates is developed in this study for the long-term analysis of two-way HSC wall panels. A time-stepping analysis is used to account for the effect of creep. A rheological material model is adopted, which is based on the generalized Maxwell chain. In order to highlight the effect of creep only, a linear viscoelastic material behavior is assumed for concrete. The incremental governing equations are solved numerically at each time step based on a Fourier series expansion of the deformations and loads in one direction and using the 
numerical multiple shooting method in the other direction. The mathematical formation of the model is presented first, followed by numerical and parametric studies.

\section{Mathematical Formulation}

The mathematical formulation includes derivation of incremental equilibrium equations, constitutive relations, and governing equations of two-way panels. The general governing equations derived here are applicable to any combination of external loads and boundary conditions. They are refined in the subsequent numerical studies to represent typical loading and edge support conditions of two-way HSC wall panels. An incremental time-stepping analysis is implemented in order to account for time-dependent variation in internal stresses and increase in deformations of the wall panel with time due to creep. For this, the time of concern $t$, which is measured from the time of first loading, is subdivided into $n_{t}$ discrete time steps with $\Delta t_{r}=t_{r}-t_{r-1}$ $\left(r=1,2, \ldots, n_{t}\right)$. The sign conventions for the coordinates, loads, and displacements are shown in Figure 1. The middle plane of the panel is taken as the $x y$ plane, where the $x$ and $y$ axes are directed along the edges. The $z$ axis is taken normal to the middle plane and measured positive out of paper (right-hand rule). The forces and bending moments at the boundaries as well as the lateral loads are also presented in Figure 1. The torsional moments at the boundaries are not shown in the figure for brevity and clarity.

2.1. Kinematic Relations. In typical HSC wall panels, the dimension in the $z$ direction and the thickness is much

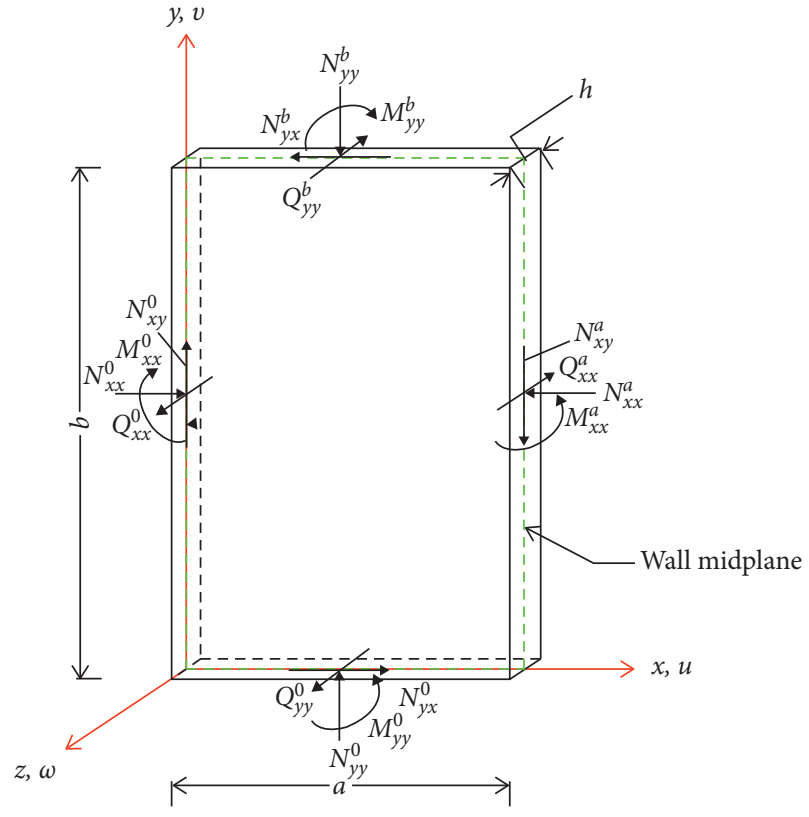

FIGURE 1: Sign conventions of the investigated panel.

smaller than those in the other two directions. Therefore, a plane stress condition is adopted, where the stresses in the $z$ direction including the normal and shear stresses are equal to zero. The theoretical model is based on Von Karman plate with large displacements. The incremental kinematic relations of the plate read

$$
\begin{aligned}
\Delta \varepsilon_{x x}\left(t_{r}\right)= & \frac{\partial \Delta u\left(t_{r}\right)}{\partial x}+\frac{1}{2}\left(\frac{\partial \Delta w\left(t_{r}\right)}{\partial x}\right)^{2}+\frac{\partial w\left(t_{r-1}\right)}{\partial x} \frac{\partial \Delta w\left(t_{r}\right)}{\partial x}-z \frac{\partial^{2} \Delta w\left(t_{r}\right)}{\partial x^{2}} \\
\Delta \varepsilon_{y y}\left(t_{r}\right)= & \frac{\partial \Delta v\left(t_{r}\right)}{\partial y}+\frac{1}{2}\left(\frac{\partial \Delta w\left(t_{r}\right)}{\partial y}\right)^{2}+\frac{\partial w\left(t_{r-1}\right)}{\partial y} \frac{\partial \Delta w\left(t_{r}\right)}{\partial y}-z \frac{\partial^{2} \Delta w\left(t_{r}\right)}{\partial y^{2}} \\
\Delta \gamma_{x y}= & \frac{\partial \Delta u\left(t_{r}\right)}{\partial y}+\frac{\partial \Delta v\left(t_{r}\right)}{\partial x}-2 z \frac{\partial^{2} \Delta w\left(t_{r}\right)}{\partial x \partial y}+\frac{\partial w\left(t_{r-1}\right)}{\partial y} \frac{\partial \Delta w\left(t_{r}\right)}{\partial x} \\
& +\frac{\partial w\left(t_{r-1}\right)}{\partial x} \frac{\partial \Delta w\left(t_{r}\right)}{\partial y}+\frac{\partial \Delta w\left(t_{r}\right)}{\partial x} \frac{\partial \Delta\left(t_{r}\right)}{\partial y}
\end{aligned}
$$

where $\varepsilon_{x x}$ and $\varepsilon_{y y}$ are the total normal strains in the $x$ and $y$ directions and $\gamma_{x y}$ is the total shear strain in the $x y$ planes. Each total strain has two components: the instantaneous strain and creep strain. $u$ and $v$ are the in-plane displacements along $x$ and $y$ directions, $w$ is the out-of-plane deflection along $z$ axis, and $\partial / \partial x$ and $\partial / \partial y$ denote the partial derivatives with respect to $x$ and $y$, respectively; $\Delta$ represents the incremental operator, and note that any displacement that appear without the $\Delta$ operator is the accumulated known quantity from the previous time step.
2.2. Equilibrium Equations. The variational principle in virtual work is used to derive the nonlinear incremental equilibrium equations along with the boundary conditions, where

$$
\delta U+\delta W=0,
$$

with $\delta U$ and $\delta W$ as the internal virtual work and external virtual work and $\delta$ is the variational operator. The incremental equilibrium equations read 


$$
\begin{aligned}
& \frac{\partial \Delta N_{x x}}{\partial x}+\frac{\partial \Delta N_{x y}}{\partial y}=0 \\
& \frac{\partial \Delta N_{y y}}{\partial y}+\frac{\partial \Delta N_{x y}}{\partial x}=0, \\
& N_{x x} \frac{\partial^{2} \Delta w}{\partial x^{2}}+\Delta N_{x x} \frac{\partial^{2} w}{\partial x^{2}}+\Delta N_{x x} \frac{\partial^{2} \Delta w}{\partial x^{2}}+N_{y y} \frac{\partial^{2} \Delta w}{\partial y^{2}} \\
& +\Delta N_{y y} \frac{\partial^{2} w}{\partial y^{2}}+\Delta N_{y y} \frac{\partial^{2} \Delta w}{\partial x^{2}} \\
& +2 N_{x y} \frac{\partial^{2} \Delta w}{\partial x \partial y}+2 \Delta N_{x y} \frac{\partial^{2} w}{\partial x \partial y}+2 \Delta N_{x y} \frac{\partial^{2} \Delta w}{\partial x \partial y} \\
& \quad+\frac{\partial^{2} \Delta M_{x x}}{\partial x^{2}}+\frac{\partial^{2} \Delta M_{y y}}{\partial y^{2}}+2 \frac{\partial^{2} \Delta M_{x y}}{\partial x \partial y}=0,
\end{aligned}
$$

where $N_{x x}$ and $N_{y y}$ are the internal axial forces in the $x$ and $y$ directions and $N_{x y}$ are the internal shear force in the $x y$ plane; $M_{x x}$ and $M_{y y}$ are the internal bending moments along $x$ and $y$ axes, and $M_{x y}$ is the internal torsional bending moment. The general boundary conditions at $x=0$ and $x=a$ are given by

$$
\begin{aligned}
& \Delta N_{x x}+\Delta N_{x x}^{i}=0 \text { or } \Delta u=\Delta \bar{u} \\
& \Delta N_{x y}+\Delta N_{x y}^{i}=0 \text { or } \Delta v=\Delta \bar{v} \\
& \Delta M_{x x}-\Delta M_{x x}^{i}=0 \text { or } \frac{\partial \Delta w}{\partial x}=\frac{\partial \Delta \bar{w}}{\partial x} \\
& N_{x x} \frac{\partial \Delta w}{\partial x}+\Delta N_{x x} \frac{\partial w}{\partial x}+\Delta N_{x x} \frac{\partial \Delta w}{\partial x}+N_{x y} \frac{\partial \Delta w}{\partial y} \\
& +\Delta N_{x y} \frac{\partial w}{\partial y}+\Delta N_{x y} \frac{\partial \Delta w}{\partial y}+\frac{\partial \Delta M_{x x}}{\partial x} \\
& \quad+2 \frac{\partial \Delta M_{x y}}{\partial y}+\Delta Q_{x x}^{i}=0 \text { or } \Delta w=\Delta \bar{w}
\end{aligned}
$$

where $\bar{u}, \bar{v}$, and $\bar{w}$ are the external deformations at the edges and $i=0$ at $x=0$ and $i=a$ at $x=a$. The general boundary conditions at $y=0$ and $y=b$ are given by

$$
\begin{aligned}
& \Delta N_{y y}+\Delta N_{y y}^{i}=0 \text { or } \Delta v=\Delta \bar{v} \\
& \Delta N_{x y}+\Delta N_{y x}^{i}=0 \text { or } \Delta u=\Delta \bar{u} \\
& \Delta M_{y y}-\Delta M_{y y}^{i}=0 \text { or } \frac{\partial \Delta w}{\partial x}=\frac{\partial \Delta \bar{w}}{\partial x} \\
& N_{y y} \frac{\partial \Delta w}{\partial y}+\Delta N_{y y} \frac{\partial w}{\partial y}+\Delta N_{y y} \frac{\partial \Delta w}{\partial y}+N_{x y} \frac{\partial \Delta w}{\partial x} \\
& \quad+\Delta N_{x y} \frac{\partial w}{\partial x}+\Delta N_{x y} \frac{\partial \Delta w}{\partial x}+\frac{\partial \Delta M_{y y}}{\partial y}+2 \frac{\partial \Delta M_{x y}}{\partial x} \\
& \quad+\Delta Q_{y y}^{i}=0 \text { or } \Delta w=\Delta \bar{w},
\end{aligned}
$$

where $\bar{u}, \bar{v}$, and $\bar{w}$ are the external deformations at the edges and $i=0$ at $y=0$ and $i=b$ at $y=b$.

2.3. Constitutive Relations. The concrete is considered as linear viscoelastic which incorporates the creep effect. A rheological model which is based on the generalized Maxwell chain is used to formulate the long-term constitutive relations of concrete [23]. The relaxation moduli can be approximated as follows:

$$
\begin{aligned}
& R_{x x}\left(t, t^{\prime}\right)=\frac{E_{c}}{(1-\nu)\left[1+\varphi\left(t, t^{\prime}\right)\right]}, \\
& R_{y y}\left(t, t^{\prime}\right)=\frac{E_{c}}{(1-\nu)\left[1+\varphi\left(t, t^{\prime}\right)\right]}, \\
& R_{x y}\left(t, t^{\prime}\right)=\frac{G_{c}}{1+\varphi\left(t, t^{\prime}\right)},
\end{aligned}
$$

where $R_{x x}\left(t, t^{\prime}\right), R_{y y}\left(t, t^{\prime}\right)$, and $R_{x y}\left(t, t^{\prime}\right)$ are the relaxation moduli in $x$ and $y$ directions and $x y$ plane, $\varphi\left(t, t^{\prime}\right)$ is the creep coefficient of the concrete at time $t$ for a load applied at time $t^{\prime}, E_{c}$ and $G_{c}$ are the elastic and shear moduli of concrete, and $v$ is Poisson's ratio, which is assumed to be time-independent [24]. Thus, due to the lack of experimental data regarding the creep behavior of concrete in shear, the latter is assumed to be similar to the creep behavior under normal stresses. The relaxation moduli can be expanded into Dirichlet series as follows:

$$
\begin{aligned}
& R_{x x}\left(t-t^{\prime}\right) \approx \bar{R}_{x x}\left(t-t^{\prime}\right) \\
& =\sum_{\mu=1}^{m} E_{\mu} e^{-\left(\left(t-t^{\prime}\right) / \tau_{\mu}\right)}+E_{m+1}, \\
& R_{y y}\left(t-t^{\prime}\right) \approx \bar{R}_{y y}\left(t-t^{\prime}\right) \\
& =\sum_{\mu=1}^{m} E_{\mu} e^{-\left(\left(t-t^{\prime}\right) / \tau_{\mu}\right)}+E_{m+1}, \\
& R_{x y}\left(t-t^{\prime}\right) \approx \bar{R}_{x y}\left(t-t^{\prime}\right) \\
& =\sum_{\mu=1}^{m} G_{\mu} e^{-\left(\left(t-t_{1}\right) / \tau_{\mu}\right)}+G_{m+1},
\end{aligned}
$$

where $\bar{R}_{x x}, \bar{R}_{y y}$, and $\bar{R}_{x y}$ are the approximated relaxation moduli, $E_{\mu}$ and $G_{\mu}$ are the moduli of the $\mu$ th spring in the Maxwell chain for the modelling in the normal and shear directions, $m$ is the number of units, and $\tau_{\mu}$ is the relaxation time of the $\mu$ th unit. Note that, in this study, $m$ and $\tau_{\mu}$ are assumed to be identical in the normal and shear directions for simplicity. The incremental constitutive relations of plane stress state can be formulated as follows based on numerical time integration: 


$$
\begin{aligned}
& \Delta \sigma_{x x}\left(t_{r}\right)=\frac{E^{\prime \prime}\left(t_{r}\right)}{1-v^{2}}\left[\Delta \varepsilon_{x x}\left(t_{r}\right)-\Delta \varepsilon_{x x}^{\prime \prime}\left(t_{r}\right)+v\left(\Delta \varepsilon_{y y}\left(t_{r}\right)-\Delta \varepsilon_{y y}^{\prime \prime}\left(t_{r}\right)\right)\right], \\
& \Delta \sigma_{y y}\left(t_{r}\right)=\frac{E^{\prime \prime}\left(t_{r}\right)}{1-v^{2}}\left[\Delta \varepsilon_{y y}\left(t_{r}\right)-\Delta \varepsilon_{y y}^{\prime \prime}\left(t_{r}\right)+v\left(\Delta \varepsilon_{x x}\left(t_{r}\right)-\Delta \varepsilon_{x x}^{\prime \prime}\left(t_{r}\right)\right)\right], \\
& \Delta \sigma_{x y}\left(t_{r}\right)=G^{\prime \prime}\left(t_{r}\right)\left(\Delta \gamma_{x y}\left(t_{r}\right)-\Delta \gamma_{x y}^{\prime \prime}\left(t_{r}\right)\right),
\end{aligned}
$$

where $E^{\prime \prime}\left(t_{r}\right)$ and $G^{\prime \prime}\left(t_{r}\right)$ are the pseudonormal and shear moduli and $\Delta \varepsilon_{x x}^{\prime \prime}\left(t_{r}\right), \Delta \varepsilon_{y y}^{\prime \prime}\left(t_{r}\right)$, and $\Delta \gamma_{x y}^{\prime \prime}\left(t_{r}\right)$ are the incremental prescribed normal strains in $x$ and $y$ directions and shear strain in the $x y$ plane that includes the effect of creep. These are given by

$$
\begin{aligned}
E^{\prime \prime}\left(t_{r}\right)= & \sum_{\mu=1}^{m}\left(1-e^{-\Delta t_{r} / \tau_{\mu}}\right) \frac{\tau_{\mu}}{\Delta t_{r}} E_{\mu}+E_{m+1}, \\
G^{\prime \prime}\left(t_{r}\right)= & \sum_{\mu=1}^{m}\left(1-e^{-\Delta t_{r} / \tau_{\mu}}\right) \frac{\tau_{\mu}}{\Delta t_{r}} G_{\mu}+G_{m+1}, \\
\Delta \varepsilon_{x x}^{\prime \prime}\left(t_{r}\right)= & \frac{1}{E^{\prime \prime}\left(t_{r}\right)} \sum_{\mu=1}^{m}\left(1-e^{-\Delta t_{r} / \tau_{\mu}}\right)\left[\sigma_{\mu}^{x x}\left(t_{r-1}\right)-v \sigma_{\mu}^{y y}\left(t_{r-1}\right)\right], \\
\Delta \varepsilon_{y y}^{\prime \prime}\left(t_{r}\right)= & \frac{1}{E^{\prime \prime}\left(t_{r}\right)} \sum_{\mu=1}^{m}\left(1-e^{-\Delta t_{r} / \tau_{\mu}}\right)\left[\sigma_{\mu}^{y y}\left(t_{r-1}\right)-v \sigma_{\mu}^{x x}\left(t_{r-1}\right)\right], \\
\Delta \gamma_{x y}^{\prime \prime}= & \frac{1}{G^{\prime \prime}\left(t_{r}\right)} \sum_{\mu=1}^{m}\left(1-e^{-\Delta t_{r} / \tau_{\mu}}\right) \sigma_{\mu}^{x y}\left(t_{r-1}\right), \\
\sigma_{\mu}^{x y}\left(t_{r}\right)= & e^{-\Delta t_{r} / \tau_{\mu}} \sigma_{\mu}^{x y}\left(t_{r-1}\right)+G_{\mu} \Delta \gamma_{x y}\left(t_{r}\right)\left(1-e^{-\Delta t_{r} / \tau_{\mu}}\right) \frac{\tau_{\mu}}{\Delta t_{r}} \\
\sigma_{\mu}^{x x}\left(t_{r}\right)= & e^{-\Delta t_{r} / \tau_{\mu}} \sigma_{\mu}^{x x}\left(t_{r-1}\right)+\frac{E_{\mu}}{1-v^{2}}\left[\Delta \varepsilon_{x x}\left(t_{r}\right)+v \Delta \varepsilon_{y y}\left(t_{r}\right)\right] \\
& \cdot\left(1-e^{\left.-\Delta t_{r} / \tau_{\mu}\right)} \frac{\tau_{\mu}}{\Delta t_{r}},\right. \\
\sigma_{\mu}^{y y}\left(t_{r}\right)= & e^{-\Delta t_{r} / \tau_{\mu}} \sigma_{\mu}^{y y}\left(t_{r-1}\right)+\frac{E_{\mu}}{1-v^{2}}\left[\Delta \varepsilon_{y y}\left(t_{r}\right)+v \Delta \varepsilon_{x x}\left(t_{r}\right)\right] \\
-\Delta t_{r} / \tau_{\mu} & \tau_{\mu} \\
& \left(1-t_{r}\right.
\end{aligned}
$$

where $\sigma_{\mu}^{x x}, \sigma_{\mu}^{y y}$, and $\sigma_{\mu}^{x y}$ are the stresses in the $\mu$ th Maxwell unit. $G^{\prime \prime}\left(t_{r}\right)$ and $G_{\mu}$ are given by $G^{\prime \prime}\left(t_{r}\right)=\left(E^{\prime \prime}\left(t_{r}\right) /[2(1+v)]\right)$ and $G_{\mu}=\left(E_{\mu} /[2(1+v)]\right)$. The constitutive relations at the cross-section level of the panel are determined using the classical definition of stress resultants and using the constitutive relations in equation (11) and the kinematic relations in equation (1) as follows:

$$
\begin{aligned}
& \Delta N_{x x}\left(t_{r}\right)=C^{\prime \prime}\left[\begin{array}{c}
\frac{\partial \Delta u}{\partial x}+\frac{1}{2}\left(\frac{\partial \Delta w}{\partial x}\right)^{2}+\frac{\partial w\left(t_{r-1}\right)}{\partial x} \frac{\partial \Delta w}{\partial x} \\
+\nu\left(\frac{\partial \Delta v}{\partial y}+\frac{1}{2}\left(\frac{\partial \Delta w}{\partial y}\right)^{2}+\frac{\partial w\left(t_{r-1}\right)}{\partial y} \frac{\partial \Delta w}{\partial y}\right)
\end{array}\right] \\
& -\Delta \bar{N}_{x x}\left(t_{r}\right), \\
& \Delta N_{y y}\left(t_{r}\right)=C^{\prime \prime}\left[\begin{array}{c}
\frac{\partial \Delta v}{\partial y}+\frac{1}{2}\left(\frac{\partial \Delta w}{\partial y}\right)^{2}+\frac{\partial w\left(t_{r-1}\right)}{\partial y} \frac{\partial \Delta w}{\partial y} \\
+v\left(\frac{\partial \Delta u}{\partial x}+\frac{1}{2}\left(\frac{\partial \Delta w}{\partial x}\right)^{2}+\frac{\partial w\left(t_{r-1}\right)}{\partial x} \frac{\partial \Delta w}{\partial x}\right)
\end{array}\right] \\
& -\Delta \bar{N}_{y y}\left(t_{r}\right), \\
& \Delta N_{x y}\left(t_{r}\right)=\frac{1-v}{2} C^{\prime \prime}\left[\begin{array}{l}
\frac{\partial \Delta u}{\partial y}+\frac{\partial \Delta v}{\partial x}+\frac{\partial w\left(t_{r-1}\right)}{\partial x} \frac{\partial \Delta w}{\partial y} \\
+\frac{\partial w\left(t_{r-1}\right)}{\partial y} \frac{\partial \Delta w}{\partial x}+\frac{\partial \Delta w}{\partial x} \frac{\partial \Delta w}{\partial y}
\end{array}\right] \\
& -\Delta \bar{N}_{x y}\left(t_{r}\right) \text {, } \\
& \Delta M_{x x}\left(t_{r}\right)=-D^{\prime \prime}\left(\frac{\partial^{2} \Delta w}{\partial x^{2}}+v \frac{\partial^{2} \Delta w}{\partial y^{2}}\right)-\Delta \bar{M}_{x x}\left(t_{r}\right), \\
& \Delta M_{y y}\left(t_{r}\right)=-D^{\prime \prime}\left(\frac{\partial^{2} \Delta w}{\partial y^{2}}+\nu \frac{\partial^{2} \Delta w}{\partial x^{2}}\right)-\Delta \bar{M}_{y y}\left(t_{r}\right) \text {, } \\
& \Delta M_{x y}\left(t_{r}\right)=-(1-v) D^{\prime \prime} \frac{\partial^{2} \Delta w}{\partial x \partial y}-\Delta \bar{M}_{x y}\left(t_{r}\right),
\end{aligned}
$$

where $C^{\prime \prime}$ and $D^{\prime \prime}$ are axial and flexural viscoelastic rigidities of the two-way panel; $\Delta \bar{N}_{x x}\left(t_{r}\right)$ and $\Delta \bar{N}_{y y}\left(t_{r}\right)$ are the incremental effective axial forces in the $x$ and $y$ directions, and $\Delta \bar{N}_{x y}\left(t_{r}\right)$ is the incremental effective shear force in the $x y$ plane; and $\Delta \bar{M}_{x x}\left(t_{r}\right)$ and $\Delta \bar{M}_{y y}\left(t_{r}\right)$ are the incremental effective bending moments along $x$ and $y$ axis, and $\Delta \bar{M}_{x y}\left(t_{r}\right)$ is the incremental effective torsional bending moment. Note that the forces and bending moments are defined as the distributions of these quantities per unit width. The viscoelastic rigidities, which account for the internal reinforcement, are given by 


$$
\begin{aligned}
& C^{\prime \prime}=\frac{E^{\prime \prime}}{1-v^{2}}\left[h+(n-1) \frac{A_{s}}{b}+(n-1)\left(\frac{A_{s}^{\prime}}{b}\right)\right], \\
& D^{\prime \prime}=\frac{E^{\prime \prime}}{1-v^{2}}\left[\frac{h^{3}}{12}+(n-1) \frac{A_{s} z_{s}^{2}}{b}+(n-1)\left(\frac{A_{s}^{\prime} z_{s}^{\prime 2}}{b}\right)\right],
\end{aligned}
$$

where $h$ is the thickness of the panel; $n=\left(E_{s} / E^{\prime \prime}\right)$, in which $E_{s}$ is the elastic modulus of steel reinforcement; $A_{s}$ and $A_{s}^{\prime}$ are the areas of the steel reinforcements at the inner and outer faces of the panel; and $z_{s}$ and $z_{s}^{\prime}$ are the locations of the corresponding reinforcements measured from the midthickness of the panel. For simplicity, $A_{s}$ and $A_{s}^{\prime}$ are taken as the minimum reinforcement ratios between $x$ and $y$ directions. The effective forces and bending moments are given as

$$
\begin{aligned}
\Delta \bar{N}_{x x}\left(t_{r}\right) & =\sum_{\mu=1}^{m}\left(1-e^{-\Delta t_{r} / \tau_{\mu}}\right) N_{\mu}^{x x}\left(t_{r-1}\right)+\int_{-(h / 2)}^{(h / 2)} \frac{E^{\prime \prime}\left(t_{r}\right)}{1-\nu} \Delta \varepsilon_{s h} \mathrm{~d} z, \\
\Delta \bar{N}_{y y}\left(t_{r}\right) & =\sum_{\mu=1}^{m}\left(1-e^{-\Delta t_{r} / \tau_{\mu}}\right) N_{\mu}^{y y}\left(t_{r-1}\right)+\int_{-(h / 2)}^{(h / 2)} \frac{E^{\prime \prime}\left(t_{r}\right)}{1-v} \Delta \varepsilon_{s h} \mathrm{~d} z, \\
\Delta \bar{N}_{x y}\left(t_{r}\right) & =\sum_{\mu=1}^{m}\left(1-e^{-\Delta t_{r} / \tau_{\mu}}\right) N_{\mu}^{x y}\left(t_{r-1}\right)+\int_{-(h / 2)}^{(h / 2)} \frac{E^{\prime \prime}\left(t_{r}\right)}{2(1+v)} \Delta \varepsilon_{s h} \mathrm{~d} z, \\
\Delta \bar{M}_{x x}\left(t_{r}\right) & =\sum_{\mu=1}^{m}\left(1-e^{-\Delta t_{r} / \tau_{\mu}}\right) M_{\mu}^{x x}\left(t_{r-1}\right)+\int_{-(h / 2)}^{(h / 2)} \frac{E^{\prime \prime}\left(t_{r}\right) z}{1-v} \Delta \varepsilon_{s h} \mathrm{~d} z, \\
\Delta \bar{M}_{y y}\left(t_{r}\right) & =\sum_{\mu=1}^{m}\left(1-e^{-\Delta t_{r} / \tau_{\mu}}\right) M_{\mu}^{y y}\left(t_{r-1}\right)+\int_{-(h / 2)}^{(h / 2)} \frac{E^{\prime \prime}\left(t_{r}\right) z}{1-v} \Delta \varepsilon_{s h} \mathrm{~d} z, \\
\Delta \bar{M}_{x y}\left(t_{r}\right) & =\sum_{\mu=1}^{m}\left(1-e^{-\Delta t_{r} / \tau_{\mu}}\right) M_{\mu}^{x y}\left(t_{r-1}\right)+\int_{-(h / 2)}^{(h / 2)} \frac{E^{\prime \prime}\left(t_{r}\right) z}{2(1+v)} \Delta \varepsilon_{s h} \mathrm{~d} z .
\end{aligned}
$$

2.4. Governing Equations. The incremental governing equations are formulated by substitution of the stress resultants in equations (15)-(19) into the equilibrium equations of equations (3)-(4), noting that terms of higher product of the incremental displacements and forces are neglected due to the use of sufficiently small time increments. The incremental governing equations are partial differential equations in terms of the unknown displacements:

$$
\psi_{p}(\Delta u, \Delta v, \Delta w)=0, \quad(p=1,2,3),
$$

where $\psi_{p}$ consists of differential operators. For brevity, the explicit form of these equations is not presented here. The equations and the boundary conditions (equations (5)-(8)) are reduced to a set of ordinary differential equations by a separation of variables and expansion into the truncated Fourier series $[24,25]$ :

$$
\begin{aligned}
\{\Delta & u(x, y), \Delta v(x, y), \Delta w(x, y)\} \\
= & \sum_{m=1}^{2 F}\left\{\Delta u_{m}(x), \Delta v_{m}(x), \Delta w_{m}(x)\right\} g_{m}(y),
\end{aligned}
$$

where $F=\left(F_{u}, F_{v}\right.$, or $\left.F_{w}\right)$ is the number of terms in the relevant Fourier series. The initial state or previous accumulated displacements and the external loads along the panel and at the boundaries take the following form:

$$
\begin{aligned}
& \{u(x, y), v(x, y), w(x, y)\} \\
& =\sum_{m=1}^{2 F}\left\{u_{m}(x), v_{m}(x), w_{m}(x)\right\} g_{m}(y), \\
& \left\{\begin{array}{c}
Q_{x x}^{0}(x, y), Q_{x x}^{a}(x, y), N_{x x}^{0}(x, y), \\
N_{x x}^{a}(x, y), M_{x x}^{0}(x, y), M_{x x}^{a}(x, y)
\end{array}\right\} \\
& =\sum_{m=1}^{2 F}\left\{\begin{array}{c}
Q_{x x m}^{0}(x), Q_{x x m}^{a}(x), N_{x x m}^{0}(x), \\
N_{x x m}^{a}(x), M_{x x m}^{0}(x), M_{x x m}^{a}(x)
\end{array}\right\} g_{m}(y), \\
& \left\{\begin{array}{c}
Q_{y y}^{0}(x, y), Q_{y y}^{b}(x, y), N_{y y}^{0}(x, y), \\
N_{y y}^{b}(x, y), M_{y y}^{0}(x, y), M_{y y}^{b}(x, y)
\end{array}\right\} \\
& =\sum_{m=1}^{2 F}\left\{\begin{array}{c}
Q_{y y m}^{0}(x), Q_{y y m}^{b}(x), N_{y y m}^{0}(x), \\
N_{y y m}^{b}(x), M_{y y m}^{0}(x), M_{y y m}^{b}(x)
\end{array}\right\} g_{m}(y), \\
& q_{z}(x, y)=\sum_{m=1}^{2 F} q_{z m}(x) g_{m}(y)
\end{aligned}
$$

The functions $g_{m}(y)$ are 


$$
g_{m}(y)=\left\{\begin{array}{l}
\sin \left(\frac{m \pi}{b} y\right), \quad m=1,2, \ldots, F \\
\cos \left[\frac{(m-F) \pi}{b} y\right], \quad m=F+1, F+2, \ldots, 2 F .
\end{array}\right.
$$

By minimizing the errors due to the truncated Fourier series by the Galerkin procedure with trigonometric weighting functions, the partial differential equations are converted into linear ordinary differential equations in the $x$ direction:

$$
\Psi_{p}^{m}(x)=\int_{0}^{b} \psi_{p}(u, v, w) g_{m}(y) \mathrm{d} y, \quad(p=1,2,3 ; m=1,2, \ldots, 2 F) .
$$

The governing equations along with the boundary conditions are solved through the use of the multiple shooting method at each time step $[25,26]$. The analysis presented here is also conducted up to a certain time (the critical time) where the deformations of the system exceed a prescribed limit $[27,28]$. A proper time step is selected for a given load level in the way that the difference between the predicted critical times of creep buckling for the selected time-step and one-half of it is of minor significance.

\section{Numerical Study}

3.1. Numerical Example. The wall panel studied here is $5000 \mathrm{~mm}$ high $(b), 3500 \mathrm{~mm}$ long $(a)$, and $150 \mathrm{~mm}$ thick $(h)$. The compressive strength and elastic modulus of the concrete are $f_{c}=80 \mathrm{MPa}$ and $E_{c}=39.6 \mathrm{GPa}$, respectively. The panel is assumed to be loaded at the age of 28 days. The creep coefficient is calculated following AS3600, which is given by

$$
\varphi(t)=\frac{1.45 t^{0.8}}{t^{0.8}+17} .
$$

The number of Maxwell units $(m)$ used to model the viscoelastic behavior of concrete is taken as five in this example with $\tau_{\mu}=5^{\mu-1}$ (days). The spring constants in the Maxwell model yielded by the least square methods are $E_{1}=1684 \mathrm{MPa}, \quad E_{2}=7537 \mathrm{MPa}, \quad E_{3}=8674 \mathrm{MPa}$, $E_{4}=4050 \mathrm{MPa}, E_{5}=1199 \mathrm{MPa}$, and $E_{6}=16287 \mathrm{MPa}$. The wall is assumed to be reinforced both vertically ( $y$ direction) and horizontally ( $x$ direction) at both faces. The reinforcement ratios in the $x$ and $y$ directions $\left(\rho_{x}\right.$ and $\rho_{y}$ ), defined by the total reinforcement area divided by the cross-sectional area of the member, is taken as $0.2 \%$ in each direction. The elastic modulus of the steel reinforcement is taken as $200 \mathrm{GPa}\left(E_{s}\right)$ in the study. $20 \mathrm{~mm}$ concrete cover is applied to the reinforcement. In this study, the wall panel is considered to be simply supported along 4 edges and subjected to uniform inplane sustained compression loads eccentrically applied at top and bottom ends in the vertical $(y)$ direction. The wall is not taking any out-of-plane transverse loads. This leads to $N_{x y}^{0}=N_{x y}^{a}=N_{x y}^{b}=N_{x x}^{0}=N_{x x}^{a}=0$. The vertical compression loads imposed on the top and bottom edges equal $22.4 \mathrm{kN} / \mathrm{mm}\left(N_{y y}^{0}=N_{y y}^{b}=22.4(\mathrm{kN} / \mathrm{mm})\right)$, which equals to
$60 \%$ of the elastic buckling load $\left(P_{c r}=37.3 \mathrm{kN} / \mathrm{mm}\right)$, that is determined according to the classical equation given as follows [29]:

$$
\begin{aligned}
P_{c r}= & \frac{4 D^{\prime \prime} \pi^{2}}{b^{2}}=\frac{4 \pi^{2}}{b^{2}} \frac{E_{c}}{1-v^{2}}\left[\frac{h^{3}}{12}+(n-1)\left(\frac{A_{s x} z_{s x}^{2}}{b}\right)\right. \\
& \left.+(n-1)\left(\frac{A_{s x}^{\prime} z_{s x}^{\prime 2}}{b}\right)\right] .
\end{aligned}
$$

The eccentricities $(e)$ at both edges are $h / 6$, which is equal to $25 \mathrm{~mm}$. The eccentricity is considered in the mathematical model by applying vertical axial compression loads along the top and bottom edges $\left(N_{y y}^{0}\right.$ and $\left.N_{y y}^{b}\right)$ and out-of-plane bending moments $M_{y y}^{0}$ and $M_{y y}^{b}$ along both ends, whose magnitude is equal to $N_{y y}^{0} \cdot e$ and $N_{y y}^{b} \cdot e$ In this numerical example, the end bending moments are both positive.

The time-dependent variation in the out-of-plane deflection and the bending moments at the center of the panel are shown in Figures 2 and 3. The time $t$ is measured since the time of first loading. The deflection is normalized with respect to the thickness of the panel $h$. It can be seen that the deflection of the panel and hence the bending moments $M_{x x}$ and $M_{y y}$ increase with time as a result of the combined effects of creep and geometric nonlinearity. The out-of-plane deflection as well as the bending moment tends to asymptotically increase towards infinity beyond a certain time. The buckling failure is considered to occur when the normalized out-of-plane deflection $(w / h)$ reaches a given limit. The limit in this numerical study is taken as 4 , and the corresponding time, referred to as the critical time, equals 4900 days in this case. As indicated in Figure 3(b), the ratio of $M_{y y} / M_{x x}$ also increases with time, which implies that stress redistribution occurs with time, and the influence of the geometric nonlinearity becomes more pronounced in the $x$ direction than in the $y$ direction.

The out-of-plane deflection distribution and the bending moments $M_{x x}$ and $M_{y y}$ distribution along $x$ and $y$ directions at various times are shown in Figures 4-6. The result shows that the time-dependent increase in the out-of-plane deflection caused significant increase in bending moments in both $x$ and $y$ directions. It also demonstrates the ability of the proposed theoretical model in predicting and describing the time-dependent response of thin panels. It is clear by inspecting Figure 6 that, due to the creep and geometric nonlinearity, the bending moment $M_{y y}$ is increasing with time, and at some time, the maximum bending moment may appear at the center rather than at the edges which is the location of maximum $M_{y y}$ for the panel under instantaneous loading. The shift of the maximum deflection $w$ and bending moments $M_{y y}$ from the edges to the middle as time goes should be carefully taken into consideration in designing the concrete panels as the maximum values in the $y$ direction appear at different locations for short-term response and long-term response. Failure to recognize these time effects may result in unexpected serviceability problems such as excessive deflection and cracking or even structural failure over time. 


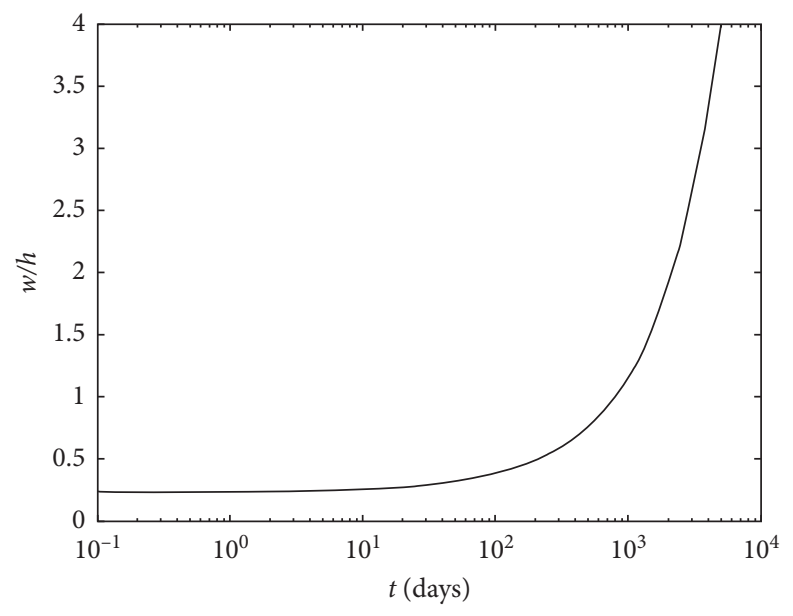

(a)

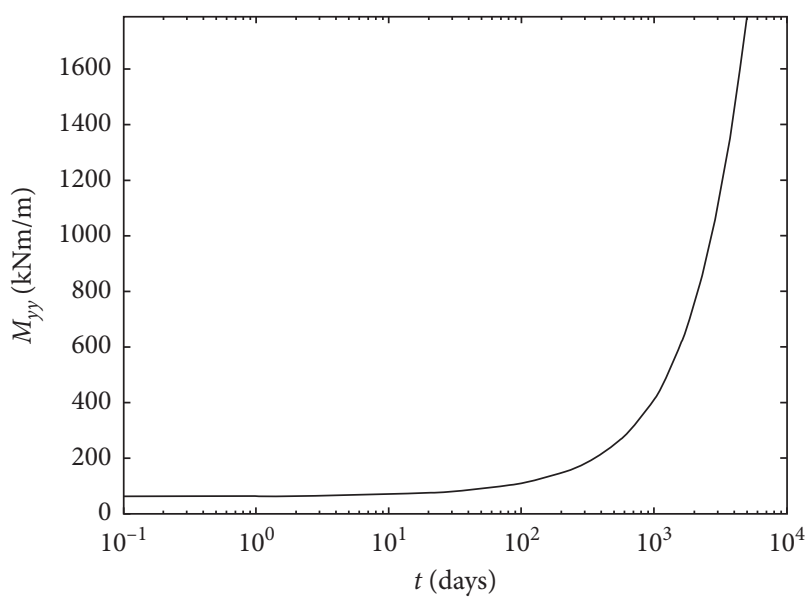

(b)

FIgURE 2: Variation with time of (a) out-of-plane deflection and (b) bending moment $M_{y y}$ at the center of the panel.

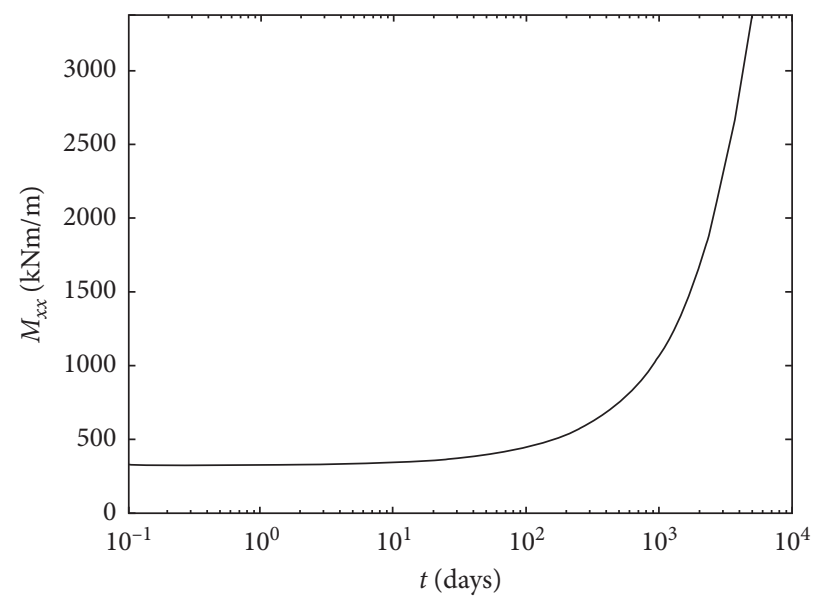

(a)

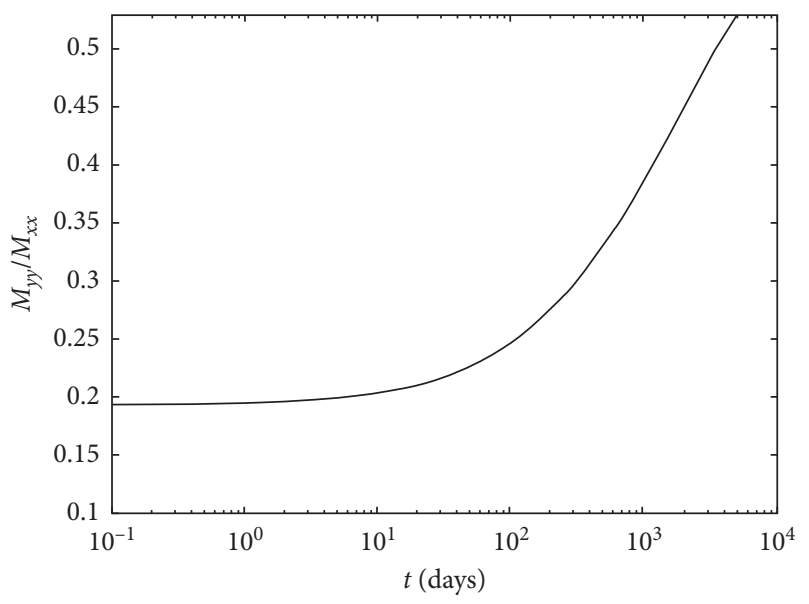

(b)

FIGURE 3: Variation with time of (a) bending moment $M_{x x}$ and (b) the ratio of $M_{y y} / M_{x x}$ at the center of the panel.

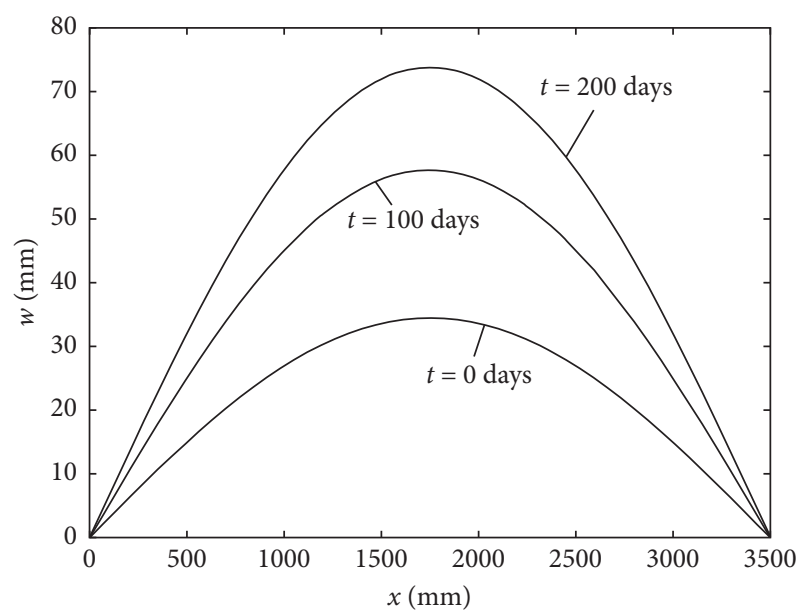

(a)

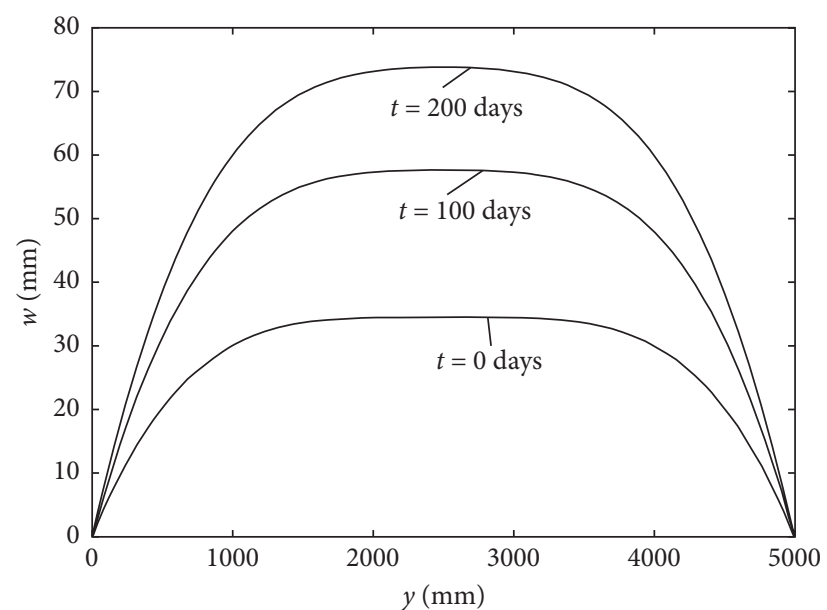

(b)

Figure 4: Deflection distribution through the $x$ direction (a) and $y$ direction (b) at three different times. 


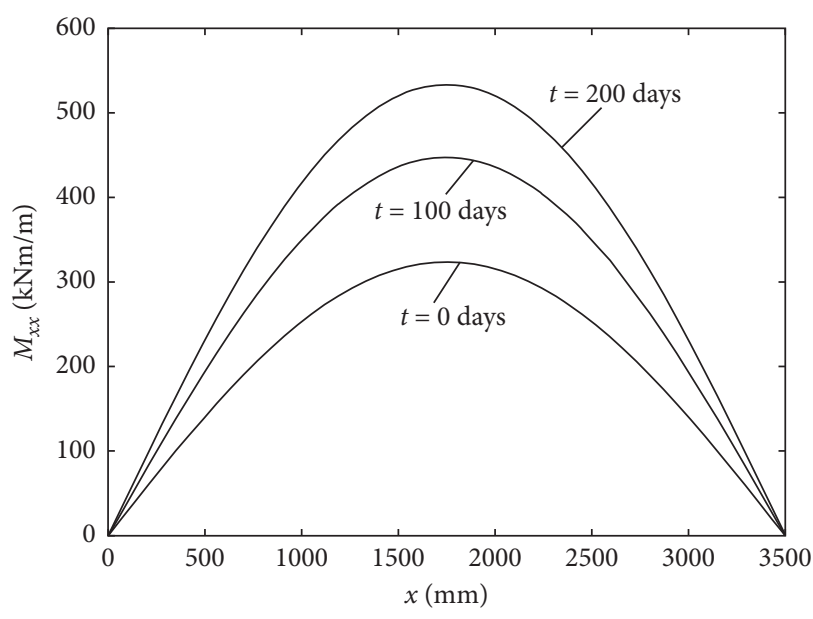

(a)

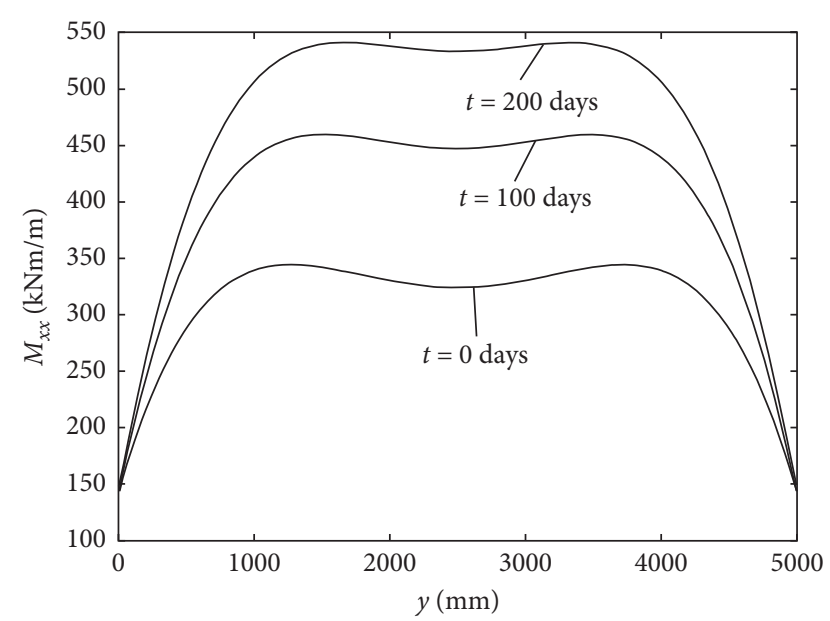

(b)

Figure 5: Bending moment $M_{x x}$ distribution through $x$ direction (a) and $y$ direction (b) at three different times.

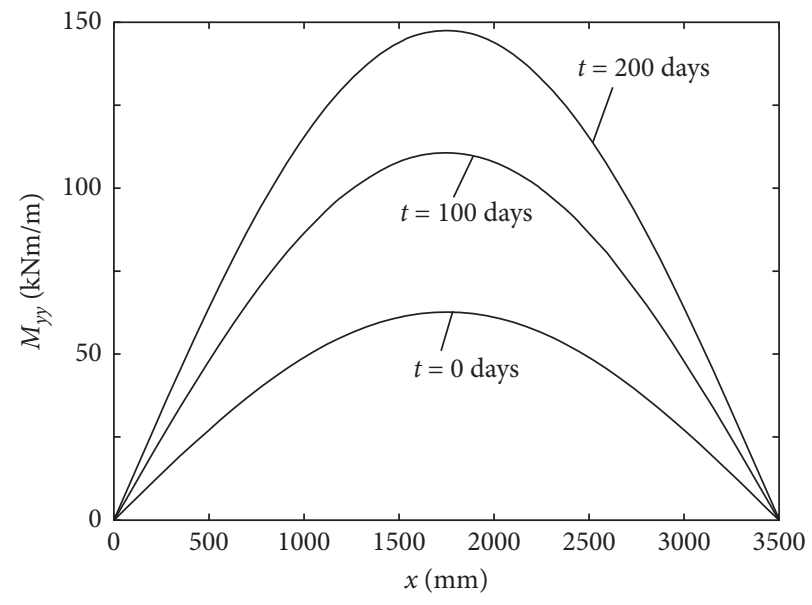

(a)

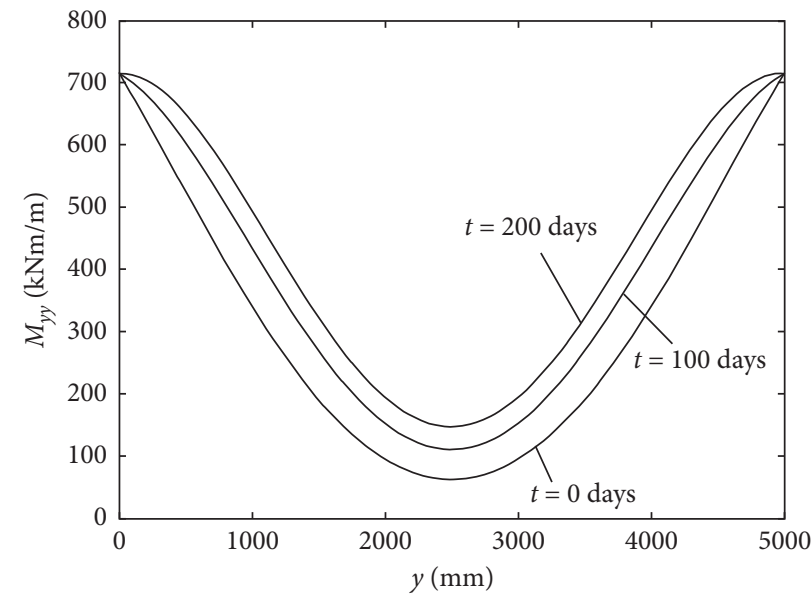

(b)

Figure 6: Bending moment $M_{y y}$ distribution through $x$ direction (a) and $y$ direction (b) at three different times.

3.2. Parametric Study. A parametric study is carried out in this section to examine the effects of the key factors on the time-dependent response of HSC panels. The factors include the magnitude and eccentricity of the sustained in-plane load $\left(N_{y y}^{0}\right)$, the slenderness ratio defined as $b / h$, boundary conditions, and the aspect ratio defined as $a / b$. A $2 \mathrm{~m} \times 2 \mathrm{~m}$ square panel is used as a reference to compare with other panels. All other panels investigated here have the same dimensions as the reference panel unless specifically stated. Moreover, they contain equal reinforcement ratios in both orthogonal directions $\left(\rho_{x}=\rho_{y}\right)$ and are equally reinforced at both faces.

\subsubsection{Effect of Load Level. Figure 7 presents the influence of} the level of the sustained load on the time-dependent behaviour of the reference two-way HSC panel that is simply supported on four edges. For all load levels, the same dimensions, eccentricity, reinforcement ratios $\left(\rho_{x}=\rho_{y}=0.2 \%\right)$, and material properties are applied. It can be seen that the increase in the imposed load level leads to earlier occurrence of buckling (shorter critical time). It can also be observed that the panel studied here is stable in the long run under load level that is lower than $50 \%$ of the elastic buckling load $P_{c r}$, as the increase in the out-of-plane deflection stops increasing and becomes almost constant after a certain time. The minimum load level to cause creep buckling for the examined panel is $51 \%$ of its elastic buckling load. This result is in accordance with that obtained using the simplified effective modulus method (EMM), where $E_{c}$ in equation (27) is replaced with $\left(E_{c} /\left[1+\varphi\left(t, t^{\prime}\right)\right]\right)$. Nevertheless, if cracking is taken into account or biaxial loading scenarios are considered, the simplified effective modulus method might lead to inaccurate results.

3.2.2. Effect of Load Eccentricity. Figure 8 reveals the change in the out-of-plane deflection at the center of the square panel with time under the in-plane compression load with different eccentricities. The load is equal to $52 \%$ of the elastic buckling load. As seen in the figure, the time-dependent behaviour is 


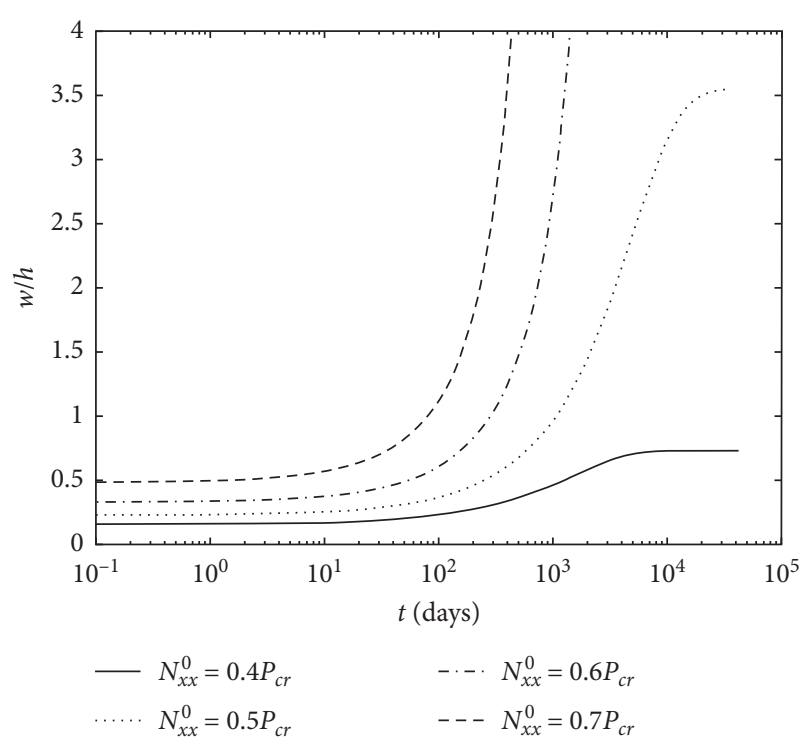

FIGURE 7: Influence of load level on the long-term behavior of the HSC panel for the square panel $\left(e=h / 6,\left[\rho_{x}, \rho_{y}\right]=0.2 \%\right.$, and $a \times b \times h=2000 \times 2000 \times 100 \mathrm{~mm})$.

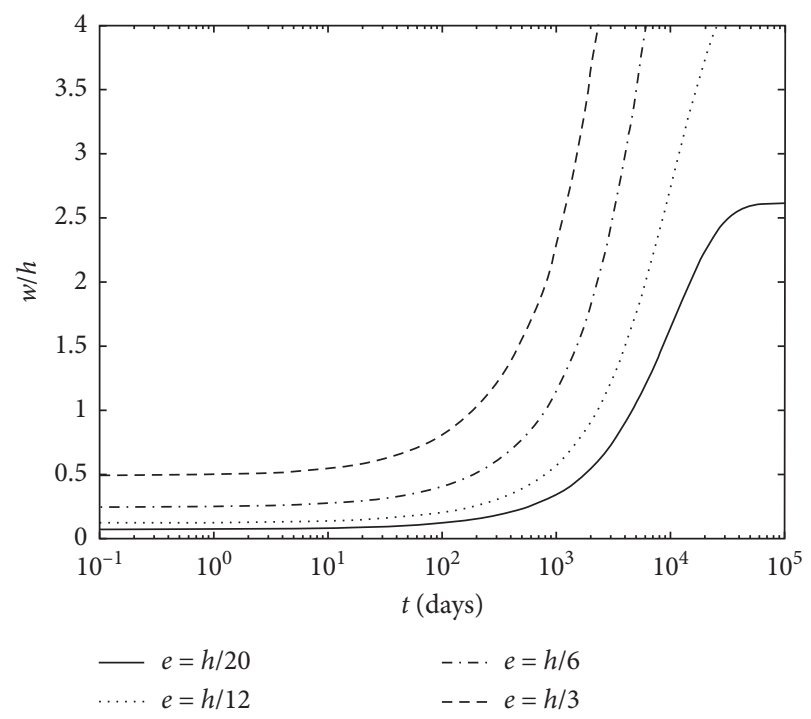

FIGURE 8: Influence of eccentricity on the long-term behavior of the square HSC panel $\left(N_{y y}^{0}=0.52 P_{c r}, \quad\left[\rho_{x}, \rho_{y}\right]=0.2 \%\right.$, and $a \times b \times h=2000 \times 2000 \times 100 \mathrm{~mm})$.

very sensitive to the eccentricity. Thus, it is essential in the design to consider different load scenarios as small inaccuracy in estimating that the actual load eccentricity may result in catastrophic buckling failure in the long term.

3.2.3. Effect of Slenderness Ratio. The normalized deflection at the center of the panels with various thicknesses is plotted against the time in Figure 9. The load level, the eccentricity, and the reinforcement ratios in both orthogonal directions are $0.6 P_{c r}, h / 6$, and $0.2 \%$, respectively, where $P_{c r}$ is the elastic buckling load corresponding to the panel with $100 \mathrm{~mm}$ thickness in order to keep the load unchanged for the three

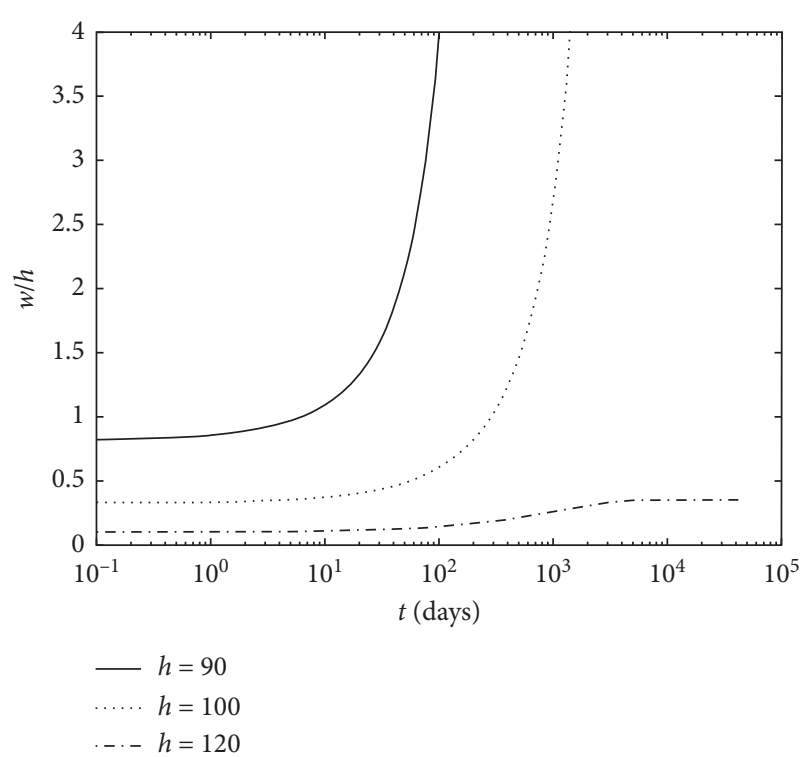

FIGURE 9: Influences of slenderness on the long-term behavior of the square HSC panel $\left(N_{y y}^{0}=0.6 P_{c r}, e=h / 6,\left[\rho_{x}, \rho_{y}\right]=0.2 \%\right.$, and $a \times b=2000 \times 2000 \mathrm{~mm}$ ).

different cases. Three different thicknesses $90 \mathrm{~mm}, 100 \mathrm{~mm}$, and $120 \mathrm{~mm}$ are investigated, which give the slenderness ratios of $22.2,20$, and $16.7(b / h)$. It can be seen that, under the same magnitude of sustained load, the panels that are $90 \mathrm{~mm}$ and $100 \mathrm{~mm}$ thick are unstable, whereas the panel with $120 \mathrm{~mm}$ thickness exhibits stable behavior. For the unstable panels, the critical time increases with increasing thickness. Therefore, in practical design and use of the twoway panels, the creep buckling failure can be prevented by increasing the thickness of the panel.

3.2.4. Effect of Boundary Condition. The support conditions are varied at the top and bottom edges $(y=0$ and $y=b)$, while the side edges at $x=0$ and $x=a$ remain simply supported.

Three different cases are investigated in this section, including simply supported with eccentric loading at top and bottom edges (Case I), simply supported at top and bottom edges with concentric loading at one edge and eccentric loading at the other (Case II), and fixed support at bottom end and simply supported with eccentric loading at the other (Case III). The details are given in Table 1. The panel has the same geometric and material properties as the reference panel.

The variation in the center deflection with time for the three cases is depicted in Figure 10. It can be seen that creep buckling happens to both Case I and Case II. It can also be seen that Case I that is loaded eccentrically at both ends is more vulnerable to creep buckling. On the contrary, Case III is the stiffest one among the three cases due to the fixed support at one end, which leads to an ultimate stable state.

3.2.5. Effect of Aspect Ratio. The result for the effect of aspect ratio is shown in Figure 11, where five aspect ratios, namely, $0.5,0.75,1,1.5$, and 2 are investigated. The aspect ratios are achieved by varying the height $(b)$ of the panel, whereas the 
TABLE 1: Details of boundary conditions and loads.

\begin{tabular}{|c|c|c|c|c|c|c|}
\hline & \multicolumn{4}{|c|}{$\begin{array}{l}\text { Boundary support } \\
\text { condition }\end{array}$} & \multicolumn{2}{|c|}{ Vertical in-plane load } \\
\hline & $x=0$ & $x=a$ & $y=0$ & $y=b$ & $N_{y y}^{0}$ & $N_{y y}^{b}$ \\
\hline Case I & SS & SS & SS & SS & $\begin{array}{c}\text { Eccentric } \\
(e=h / 6)\end{array}$ & $\begin{array}{c}\text { Eccentric } \\
(e=h / 6)\end{array}$ \\
\hline $\begin{array}{l}\text { Case } \\
\text { II }\end{array}$ & SS & SS & SS & SS & $\begin{array}{c}\text { Eccentric } \\
(e=h / 6)\end{array}$ & Concentric \\
\hline $\begin{array}{l}\text { Case } \\
\text { III }\end{array}$ & SS & SS & Fixed & SS & N/A & $\begin{array}{c}\text { Eccentric } \\
(e=h / 6)\end{array}$ \\
\hline
\end{tabular}

Note. SS, simply supported.

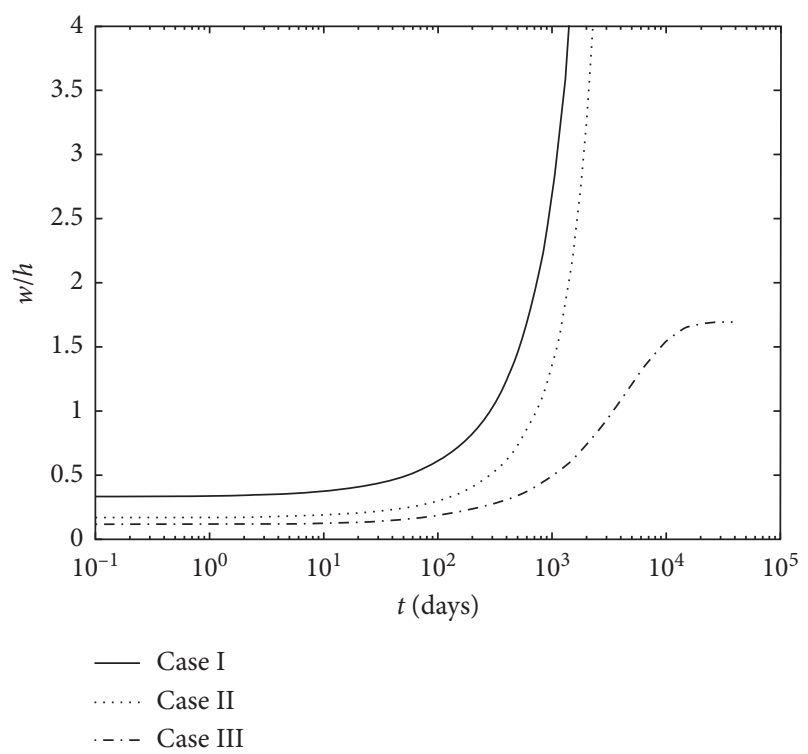

FIGURE 10: Influences of boundary conditions on the long-term behavior of the square HSC panel $\left(N_{y y}^{0}=0.6 P_{c r},\left[\rho_{x}, \rho_{y}\right]=0.2 \%\right.$, and $a \times b \times h=2000 \times 2000 \times 100 \mathrm{~mm})$.

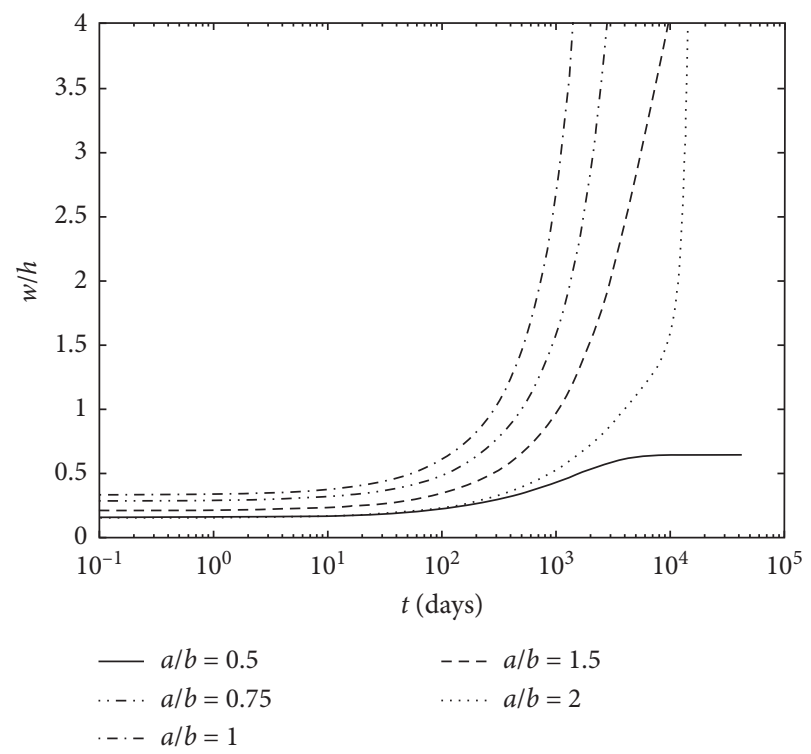

FIGURE 11: Influence of aspect ratio on the long-term behavior of the HSC panel $\left(N_{y y}^{0}=0.6 P_{c r}, e=h / 6,\left[\rho_{x}, \rho_{y}\right]=0.2 \%\right.$, and $a \times h=2000 \times 100 \mathrm{~mm})$. width $(a)$ and thickness $(h)$ remain the same as the reference panel. All panels possess the same reinforcement ratio of $0.2 \%$ in both orthogonal directions and under the in-plane compression load in the $x$ direction with $N_{y y}^{0}=0.6 P_{c r}$ and $e=h / 6$. The maximum deflections for the panels with aspect ratio from 0.5 to 1.5 appear at the center of the specimen, whereas for the panel with $b / a=2$, the maximum deflection occurs around a quarter of the height. It is observed in the figure that the long-term behavior of the two-way panel is substantially influenced by the aspect ratio, and the panel with aspect ratio of 1 is the most critical case. The critical time decreases either with the increase in the aspect ratio as long as it is larger than 1 or with the decrease in the aspect ratio when the aspect ratio is smaller than 1 . The increase in the critical time associated with the increase in aspect ratio can be explained by the fact that the panel with a greater height $(b)$ is stiffer and hence has smaller deflections under the same load level, which is obvious by observing the instantaneous deflection.

\section{Conclusions}

Reinforced high-strength concrete walls have been developed and used extensively over years. Yet, there is a shortage of studies on the long-term behavior of walls in two-way action under sustained loads such that the impact of creep effect on wall behaviors is still not clear. Even major concrete standards, such as ACI318 [8] in US and AS3600 [9] in Australia, have not incorporated the time effects of creep in wall designs. Therefore, a theoretical model is developed in this paper to investigate the time-dependent behavior of HSC two-way wall panels. The model is based on a time-stepping analysis that incorporates the variation in internal stress with time. It accounts for concrete creep through a rheological viscoelastic model that is based on generalized Maxwell chain and considers its coupling effect with geometric nonlinearity.

The capabilities of the theoretical model are examined and demonstrated through numerical examples and parametric studies. It has been shown in the numerical study that the increase in out-of-plane deflection and the internal bending moments may lead to creep buckling failures under axial sustained loads that are as low as $51 \%$ of the elastic classical buckling load. The estimated buckling strength with time is much smaller than the elastic buckling strength, which emphasizes the importance of considering these longterm effects in the design of HSC wall panels.

The parametric study carried out in this investigation reveals that some key parameters such as the level and eccentricity of in-plane vertical loads, slenderness ratio, edge support conditions, and aspect ratio are vital in determining the creep buckling response of HSC panels. Therefore, more research is required to derive a wall panel design equation that can incorporate these crucial factors along with the time effects of creep.

\section{Data Availability}

The data used to support the findings of this study are available from the corresponding author upon request. 


\section{Conflicts of Interest}

The authors declare that there are no conflicts of interest regarding the publication of this paper.

\section{Acknowledgments}

Financial support from Australian Research Council and National Natural Science Foundation of China is gratefully acknowledged. The authors also acknowledge the guidance, expertise, and assistance provided by Dr. Ehab Hamed in the University of New South Wales, Australia. This research was funded by the Australian Research Council through a Discovery Project (grant no. DP 120102762), National Natural Science Foundation of China (grant no. 51608135), and Taishan Scholars Program of Shandong Province, China (tsqn201909127).

\section{References}

[1] G. D. Oberlender and N. J. Everard, "Investigation of reinforced concrete walls," ACI Journal, vol. 74, no. 6, pp. 256263, 1977.

[2] S. M. Saheb and P. Desayi, "Ultimate strength of RC wall panels in one-way in-plane action," Journal of Structural Engineering, vol. 115, no. 10, pp. 2617-2630, 1989.

[3] A. Gupta and B. V. Rangan, "High-strength concrete (HSC) structural walls," ACI Structural Journal, vol. 95, no. 2, pp. 194-205, 1998.

[4] S. Fragomeni and P. A. Mendis, "Instability analysis of normal- and high-strength reinforced-concrete walls," Journal of Structural Engineering, vol. 123, no. 5, pp. 680-684, 1997.

[5] S. Fragomeni and P. A. Mendis, "Applicability of current ACI318 wall design formula for high strength concrete walls," Advances in Structural Engineering, vol. 2, no. 2, pp. 103-108, 1998.

[6] J. H. Doh, "Experimental and Theoretical Studies of Normal and High Strength Concrete Wall Panels," PhD Thesis, Griffith University, Mount Gravatt, Australia, 2002.

[7] S. E. El-Metwally, A. F. Ashour, and W. F. Chen, "Instability analysis of eccentrically loaded concrete walls," Journal of Structural Engineering, vol. 116, no. 10, pp. 2862-2881, 1990.

[8] ACI318, Building Code Requirements for Structural Concrete and Commentary, American Concrete Institute, Farmington Hills, MI, USA, 2014.

[9] AS3600, AS3600-2009 Concrete Structures, Standards Association of Australia, Sydney, Australia, 2009.

[10] Y. Huang and E. Hamed, "Buckling of one-way high-strength concrete panels: creep and shrinkage effects," Journal of Engineering Mechanics, vol. 139, no. 12, pp. 1856-1867, 2013.

[11] Y. Huang, E. Hamed, Z. T. Chang et al., "Time-dependent buckling testing of eccentrically loaded slender high-strength concrete panels," ACI Structural Journal, vol. 115, no. 1, pp. 41-51, 2018.

[12] S. E. Swartz, V. H. Rosebraugh, and M. A. Berman, "Buckling test on rectangular concrete panels," ACI Journal, vol. 71, no. 1, pp. 33-39, 1974.

[13] S. M. Saheb and P. Desayi, "Ultimate strength of R.C. Wall panels in two-way in-plane action," Journal of Structural Engineering, vol. 116, no. 5, pp. 1384-1402, 1990.

[14] A. O. Aghayere and J. G. Macgregor, "Tests of reinforced concrete plates under combined in-plane and transverse loads," ACI Structural Journal, vol. 87, no. 6, pp. 615-622, 1990.

[15] M. G. Ghoneim and J. G. MacGregor, "Tests of reinforced concrete plates under combined inplane and lateral loads," ACI Structural Journal, vol. 91, no. 1, pp. 19-30, 1994.

[16] M. G. Ghoneim and J. G. MacGregor, "Behavior of reinforced concrete plates under combined inplane and lateral loads," ACI Structural Journal, vol. 91, no. 2, pp. 188-197, 1994.

[17] J. G. Sanjayan and T. Maheswaran, "Load capacity of slender high-strength concrete walls with side supports," ACI Structural Journal, vol. 96, no. 4, pp. 571-577, 1999.

[18] A. O. Aghayere and J. G. Macgregor, "Analysis of concrete plates under combined in-plane and transverse loads," $A C I$ Structural Journal, vol. 87, no. 5, pp. 539-547, 1990.

[19] B. Massicotte, J. G. MacGregor, and A. E. Elwi, "Behavior of concrete panels subjected to axial and lateral loads," Journal of Structural Engineering, vol. 116, no. 9, pp. 2324-2343, 1990.

[20] M. G. Ghoneim and J. G. MacGregor, "Prediction of the ultimate strength of reinforced concrete plates under combined inplane and lateral loads," ACI Structural Journal, vol. 91, no. 6, pp. 688-696, 1994.

[21] M. M. Attard, N. G. Minh, and S. J. Foster, "Finite element analysis of out-of-plane buckling of reinforced concrete walls," Computers \& Structures, vol. 61, no. 6, pp. 1037-1042, 1996.

[22] Y. Huang, E. Hamed, and S. J. Foster, "Creep buckling behavior of high-strength concrete panels in two-way action," in Proceedings of the Second International Conference on Performance-Based and Life-Cycle Structural Engineering, pp. 706-715, Brisbane, Australia, 2015.

[23] Z. P. Bažant and S. T. Wu, "Rate-type creep law of aging concrete based on maxwell chain," Materials and Structures, vol. 7, no. 1, pp. 45-60, 1974.

[24] Z. P. Bažant, Mathematical Modelling of Creep and Shrinkage of Concrete, John Wiley \& Sons, Chichester, England, 1988.

[25] E. Hamed, M. Bradford, and R. I. Gilbert, "Creep buckling of imperfect thin-walled shallow concrete domes," Journal of Mechanics of Materials and Structures, vol. 5, no. 1, pp. 107-128, 2010.

[26] J. Stoer and R. Bulirsch, Introduction to Numerical Analysis, Springer-Verlag, New York, NY, USA, 2002.

[27] N. J. Hoff, "A survey of the theories of creep buckling," in Proceedings of the third U.S. National Congress of Applied Mechanics, pp. 29-49, American Society of Mechanical Engineers (ASME), New York, NY, USA, 1958.

[28] Z. P. Bažant and L. Cedolin, Stability of Structures: Elastic, Inelastic, Fracture and Damage Theories, Oxford University Press, New York, NY, USA, 1991.

[29] C. L. Dym and I. H. Shame, Solid Mechanics a Variational Approach, Springer Science+Business Media New York, London, UK, 2013. 